\title{
FIRMS' R\&D DILEMMA: TO UNDERTAKE OR NOT TO UNDERTAKE R\&D
}

\author{
Xulia González \\ Consuelo Pazó* \\ (Universidad de Vigo)
}

October 2002

\begin{abstract}
It is well known that in most industries a significant proportion of firms do not perform innovative activities. Although empirical studies on the determinants of $R \& D$ often have taken this fact into account by considering the dependent variable as a censured one, there is not an explicit theoretical model to explain the zeros. The concern of this letter is to discuss a simple theoretical model where firms simultaneously decide whether to undertake or not R\&D activities jointly with the level of the R\&D investment. We show that a firm performs R\&D activities only when its optimal level of R\&D expenditure is higher than a threshold. Additionally, we show that both the probability of undertaking $R \& D$ activities and the $R \& D$ expenditure increase with market power, with the elasticity of demand with respect to quality and with the elasticity of quality with respect to R\&D. Finally, from this simple theoretical framework we discuss a suitable econometric model that threats these decisions simultaneously.
\end{abstract}

JEL Classification: O32,L1,C24

Keywords: R\&D, thresholds, Tobit model.

\footnotetext{
* Facultad de CC. Económicas y Empresariales

Universidad de Vigo

As Lagoas-Marcosende, s/n

36310 Vigo

e-mail:xgzlez@uvigo.es, cpazo@uvigo.es.
} 


\section{INTRODUCTION}

The factors that influence the firm's decision to undertake research and development (R\&D) activities has long interested researchers and policy makers. Theoretical analyses of firm's R\&D determinants often overlook the fact that a significant proportion of firms do not perform actively innovative activities. ${ }^{1,2}$ Although empirical studies on the determinants of R\&D usually have taken this fact into account by modeling the dependent variable as a censured one, there is not an explicit theoretical model to explain the zeros. ${ }^{3}$

If we take firms as rational agents, then zero $R \& D$ expenditure should be considered as the outcome of an optimizing behavior based on the (expected) market profitability of such activities. Ignoring the analysis of the factors that impel or inhibit the performing of R\&D activities, the general analysis of the mechanisms that determine the level of innovative activities is incomplete. ${ }^{4}$

In this paper we try to integrate the analysis of the decision to undertake $R \& D$ activities with the analysis of the decision on the level of the R\&D investment when this investment is carried out. With this purpose, we develop a simple theoretical framework to explain simultaneously both decisions, assessing the degree to which a generalized Tobit model matches the theoretical benchmark.

The central idea of the theoretical framework is that firms can enlarge their demands by enhancing the R\&D quality, ${ }^{5}$ but this activity is subject to some technological constraints, summarized in a sales-R\&D expenditures frontier (maximum sales at each expenditure level), that will differ among industries and even among firms. In particular, we consider that innovative activities are subject to the indivisibility of some R\&D resources (and old an widely accepted idea; see, for example, Arrow (1962)). This implies that a minimum expenditure is required to improve product quality above a standard level in order to affect demand (i.e., the feasible set is not convex).

Minimum expenditure, jointly with demand characteristics and technological opportunities, determine threshold R\&D levels under which firms do not find profitable to invest. Under 
the threshold, the output effect of performing $R \& D$ is not yet big enough for $R \& D$ expenditures to be completely recovered with the profits derived from the investment. Accordingly we would take $R \& D$ investment, or alternatively the $R \& D$ effort (the ratio of R\&D expenditures to sales), as a censored variable for which we do not observe the positive values that have been discarded as non-profitable. Our econometric model is aimed at the identification of the common characteristics of the sales-R\&D frontiers and to the measurement of the thresholds and the uncovering of its determinants.

This paper is organized as follows. Section two explains the theoretical framework. Section three determines the condition under which we will observe the firms undertaking R\&D. Section four proposes a suitable econometric model and section five concludes.

\section{A THEORETICAL FRAMEWORK FOR R\&D DECISIONS}

Our theoretical framework consists of a very simple model, developed in terms of a product differentiated market that we consider monopolistically competitive. To obtain parametric conditions we suppose, in addition, that the demand specification corresponds to the well known Dixit-Stiglitz (1977) model, augmented to accommodate quality. In this framework, we introduce and specify a quality production function.

Let us consider an industry that is composed of $n$ firms, each one of them producing one

distinct brand whose output is denoted by $q_{i}$, each output presenting an associated level of quality $s_{i}, i=1, \ldots, n$. Assume there is a representative consumer that spends a fixed amount of income $Y$ on the products of the industry, whose preferences are given by the utility function

$$
U(\boldsymbol{q}, \boldsymbol{s})=\left[\sum_{i=1}^{n}\left(q_{i} s_{i} \delta\right)^{\rho}\right]^{\frac{1}{\rho}}, \quad 0<\rho<1, \delta>0
$$

where $\boldsymbol{q}=\left(q_{1}, \ldots, q_{n}\right), \boldsymbol{s}=\left(s_{1}, \ldots, s_{n}\right)$ and $\delta$ is a quality sensitivity parameter. ${ }^{6}$

Utility maximization gives demands of the form $q_{i}(\boldsymbol{p}, \boldsymbol{s})=y p_{i}^{-\eta} s_{i}^{\varepsilon}$, where $\boldsymbol{p}=\left(p_{1}, \ldots p_{n}\right)$, $\boldsymbol{s}=\left(s_{1}, \ldots s_{n}\right), \eta=1 /(1-\rho)$ is the elasticity of substitution between the quality adjusted 
goods, $\varepsilon=\delta(\eta-1)$, and $y=Y p^{-1}$, where $p=\sum_{i=1}^{n}\left(p_{i} / s_{i}^{\delta}\right)^{1-\eta}$ is a quality-adjusted price index. Note that $\partial q_{i} / \partial s_{i}>0$, and that $\partial^{2} q_{i} / \partial s_{i}^{2}>0$ if we assume $\delta \leq 1 /(1-\eta)$.

Suppose that the number of firms that operate in the industry is large enough to consider the effects of the price and quality decisions of a single firm on the aggregate price index $p$ as negligible. Then, the price and quality elasticities perceived by every firm will simply coincide with $\eta$ and $\varepsilon$.

Quality can be improved by incurring in R\&D expenditures, denoted henceforth by $x$, according to some technological rules. Our analysis will be based on two features regarding the quality production functions that seem both natural and broadly accepted. Firstly, we assume that there is a minimum amount of investment below which R\&D activities have no effect. We consider this characteristic derived from the indivisibility of some R\&D resources, ${ }^{7}$ and it will raise the existence of threshold effects. Secondly, we consider that the effectiveness of $R \& D$ expenditures is subject to diminishing returns.

According to these features we will assume that $R \& D$ expenditures below a certain level have no effect on quality, and the firm would simply attain the standard quality given by the current "state of art", $s_{0}$. Otherwise R\&D expenditures will affect quality. Then let us suppose firms can affect the quality of their products according to the following function

$$
s\left(x_{i}\right)=\left\{\begin{array}{llc}
\bar{x}^{\theta} & \text { if } & 0 \leq x_{i} \leq \bar{x} \\
x_{i}^{\theta} & \text { if } & x_{i} \geq \bar{x}
\end{array}\right.
$$

where $\theta<1$. That is, quality can be increased, although at a decreasing rate, by incurring in additional expenditures beyond a minimum level $\bar{x}$ (set-up costs) required to affect quality. On the other hand, we assume that every good can be produced at a unit $\operatorname{cost} c{ }^{8}$

Suppose that, taken as given the actions of the rivals, the firm chooses simultaneously the price of the product and the level of R\&D expenditures to affect quality. Then, solving the program 


$$
\max _{p_{i}, x_{i}} \pi_{i}=\left(p_{i}-c\right) q_{i}\left(p_{i}, s\left(x_{i}\right)\right)-x_{i}
$$

subject to the production of quality constraint, every firm determines its optimal price $p_{i}^{*}$ and its (conditional) optimal investment $x_{i}^{*}$, but as the firm can decide not to spend in R\&D at all, it chooses a pair $\left(p_{i}^{e}, x_{i}^{e}\right)$ such that

$$
\pi_{i}\left(p_{i}^{e}, x_{i}^{e}\right)=\max \left\{\pi_{i}\left(p_{i}^{*}, x_{i}^{*}\right), \pi_{i}\left(p_{i}^{* *}, 0\right)\right\} .
$$

where $p_{i}^{* *}$ is the price that the firm will set if it decides not to undertake R\&D.

\section{WHEN IS R\&D PROFITABLE?}

We will observe that the firm undertakes R\&D only if that is the most profitable alternative, that is if $\pi_{i}\left(p_{i}{ }^{*}, x_{i}{ }^{*}\right)>\pi_{i}\left(p_{i}{ }^{* *}, 0\right)$. Given our assumptions, the optimal price is $p_{i}^{*}=\eta c /(\eta-1)$ and (conditional) the optimal $\mathrm{R} \& \mathrm{D}$ expenditures can be written, $x_{i}^{*}=(\theta \varepsilon /(\eta \gamma))^{\frac{1}{1-\theta \varepsilon}} \bar{x}$, where $\gamma=\bar{x} /\left(p_{i}^{*} q_{i}\left(p_{i}^{*}, s_{0}\right)\right)$ is the ratio of minimum R\&D expenditures to the sales at optimal price and standard quality, and $p_{i}^{*}=p_{i}^{* *}$. Then, it is easy to check that $\pi_{i}\left(p_{i}^{*}, x_{i}\right)=\frac{1-\theta \varepsilon}{\eta} y p_{i}^{*(1-\eta)} x_{i}^{\theta \varepsilon}$ and $\pi_{i}\left(p_{i}^{* *}, 0\right)=\frac{1}{\eta} y p_{i}^{*(1-\eta)} \bar{x}^{\theta \varepsilon}$. Hence the threshold value, that is, the level of expenditure at which the firm would be indifferent between performing $\mathrm{R} \& \mathrm{D}$ or not, can be computed from $\pi_{i}\left(p_{i}^{*}, x_{i}\right)=\pi_{i}\left(p_{i}^{* *}, 0\right)$, and it is given by $\tilde{x}_{i}=\frac{\bar{x}}{(1-\theta \varepsilon)^{1 / \theta \varepsilon}}$.

Accordingly, we will observe a firm undertaking $\mathrm{R} \& \mathrm{D}$ only when $x_{i}^{*}>\tilde{x}_{i}$. Then, the observability condition will be given by $\frac{1}{\eta \gamma}>(\theta \varepsilon)^{-1}(1-\theta \varepsilon)^{-\frac{1-\theta \varepsilon}{\theta \varepsilon}}$.That is, the pair $\left(p_{i}^{e}, x_{i}^{e}\right)$ selected by the firm will be given by 


$$
\left(p_{i}^{e}, x_{i}^{e}\right)= \begin{cases}\left(p_{i}^{*}, x_{i}^{*}\right) & \text { if } \frac{1}{\eta \gamma}>(\theta \varepsilon)^{-1}(1-\theta \varepsilon)^{-\frac{1-\theta \varepsilon}{\theta \varepsilon}} \\ \left(p_{i}^{*}, 0\right) & \text { otherwise }\end{cases}
$$

Thus, the probability of undertaking innovative activities increases with market power $(1 / \eta)$, with elasticity of demand with respect to quality $(\varepsilon)$ and with elasticity of quality with respect to $\mathrm{R} \& \mathrm{D}$ expenditures $(\theta)$, and decreases with minimum required expenditures relative to sales $(\gamma)$.

In addition, it can be checked that optimal effort will be given by, ${ }^{9}$

$$
E_{i}^{*}=\frac{x_{i}{ }^{*}}{p_{i}{ }^{*} q_{i}{ }^{*}}=\frac{\theta \varepsilon}{\eta}
$$

but this effort will be observed only if it is higher than the threshold value, given by $\widetilde{E}_{i}=\gamma(1-\theta \varepsilon)^{-\frac{1-\theta \varepsilon}{\theta \varepsilon}}$. Then in terms of effort we would obtain the same observability condition as before.

In the simplest case developed so far, every firm in the industry will take the same action, and hence we would observe only different R\&D decisions in different industries. But the model can easily generate asymmetric outcomes. Suppose, for example, that firms are characterized by different abilities to increase quality from R\&D expenditures (different $\theta$ ) or face different minimum expenditures (different $\bar{x}$ ). Then, we can obtain equilibria where in the same industry some firms perform innovative activities and others do not.

\section{AN ECONOMETRIC SPECIFICATION}

In the previous section, we have developed a parametric example of the firm problem, using specific functional forms for the demand equation and the quality production 
function. If we propose a more general setting, we find that the optimal (conditional) effort can be express as

$$
E_{i}^{*}=\frac{p_{i}-c}{p_{i}} \frac{\partial q_{i}}{\partial s_{i}} \frac{s_{i}}{q_{i}} \frac{\partial s_{i}}{\partial x_{i}} \frac{x_{i}}{s_{i}}
$$

that is, optimal (conditional) effort depends on the price-cost margin, the elasticity of demand with respect to quality and the elasticity of quality with respect to $R \& D$ expenditures (technological opportunities). This effort will only be observed if it surpasses a threshold value $\widetilde{E}_{i}$, determined by the same factors and the minimum required expenditures (set-up cots). That is

$$
E_{i}=\left\{\begin{array}{cc}
E_{i}^{*} & \text { if } E_{i}^{*}>\widetilde{E}_{i} \\
0 & \text { otherwise }
\end{array}\right.
$$

This framework leads naturally to a Tobit-type econometric model (more specifically a type 2 generalized Tobit model, in Amemiya's (1985) terminology). The variable of interest (R\&D effort) is only observed when it is stochastically greater than a threshold, which can be specified as a linear combination of explanatory variables. To estimate an effortdeterminants equation free of selection bias, we must specify the thresholds and under the assumption that some identification conditions hold, we can also estimate these thresholds and their determinants. So, taking logs and dropping the subscript $i$ for simplicity, the econometric model could be specified as

$$
\begin{gathered}
e= \begin{cases}e^{*} & \text { if } e^{*}>\widetilde{e} \\
0 & \text { otherwise }\end{cases} \\
e^{*}=z_{1} \beta_{1}+u_{1} \\
\widetilde{e}=z_{2} \beta_{2}+u_{2}
\end{gathered}
$$

where $e^{*}=\ln \left(E^{*}\right), \widetilde{e}=\ln (\widetilde{E}), z_{1}$ and $z_{2}$ are vectors of explanatory variables, and $u_{1}$ and $u_{2}$ are random disturbances.

This type of econometric model dates back to Gronau (1973) and Nelson (1977) ${ }^{10}$, although the model we propose is particular in one aspect. The price-cost margin is a key variable for firms to evaluate the profitability of the investment and its optimal value, and hence for the 
identification of the model. But this variable must be treated as endogenous if firms set prices simultaneously to $R \& D$ expenditures. The econometric model must treat the censoring of effort taking into account the price-cost margin endogeneity.

\section{CONCLUDING REMARKS}

In this paper we propose a very simple model to analyse the firm R\&D decisions: whether or not to perform R\&D activities, and the associated level of R\&D effort (R\&D expenditure over sales). For every firm, demand depends on price and quality, and the firm chooses simultaneously the price of the product and the level of R\&D expenditures, taking as given the action of rivals. The firm can choose not to spend on innovative activities, and then it will sell at the minimum standard quality given by the "state of art". In our framework, market power (measured by the price-cost margin) interacts with demand characteristics (which give the willingness to pay for a higher quality product) and technological opportunities (which provide the ease to improve quality) to determine simultaneously $R \& D$ expenditures and the sales of the firm.

The main advantage of this framework is that it leads naturally to a Tobit-type econometric model in which the variable of interest ( $R \& D$ effort) is only observed when it is stochastically greater than a threshold, which can be specified as a linear combination of explanatory variables.

Acknowledgements:

We are very grateful to Jordi Jaumandreu for all his helpful comments and suggestions. We acknowledge financial support from CICYT, project SEC1999-1236-C02-01, and from Xunta de Galicia PGIDT00PXI30005PN. 


\section{REFERENCES}

Amemiya, T. (1985) Advanced Econometrics, Basil Blackwell.

Arrow, K. (1962) Economic Welfare and the Allocation of Resources for Inventions, in R. Nelson (ed.) The Rate and Direction of Inventive Activity, Princenton University Press.

Cohen, W.M. and S. Klepper (1992) The anatomy of industry R\&D intensity distributions, American Economic Review, 82, 773-88.

Cohen, W.M. and S. Klepper (1996) A Reprise of Size and R\&D, The Economic Journal, $106,925-51$.

Cohen, W.M. and R. Levin (1989) Empirical Studies of Innovation and Market Structure, in R. Schmalensee and R.D. Willig (eds.), Handbook of Industrial Organization, II, cap. 18, Elsevier Science Publishers.

Cohen, W.M., Levin, R. and Mowery, D.C. (1987) Firm size and R\&D intensity: A reexamination, Journal of Industrial Economics, 35, 543-63.

Crépon, B., Duguet, E., and Mairesse, J. (1998) Research, innovation, and productivity: an econometric analysis at the firm level, Economics of Innovation and New Technology, $7(2), 115-58$.

Dixit, A. and Stiglitz, J. (1977) Monopolistic Competition and Optimum Product Diversity,. The American Economic Review, 67, 297-308.

Dorfman, R. And Steiner, P.O. (1954) Optimal advertising and optimal quality, American Economic Review, 44, 826-836.

González, X., Jaumandreu, J. and Pazó, C. (2001) Barriers to innovation and subsidies effectivesness, Documento de Traballo, 0112, Universidade de Vigo.

Griliches, Z. (1990) Patent Statistics as Economic Indicators: A Survey, Journal of Economic Literature, 28, 1661-1707.

Gronau, R. (1973) The effect of Children on the Housewife's Value of Time, Journal of Political Economy, 81, 168-99.

Klette and Griliches (1997) Empirical patterns of firm growth and R\&D investment: a quality ladder model interpretation, NBER Working Paper 6945. 
Lee, C. Y. (2002) A simple model of R\&D: and extension of the Dorfman-Steiner Theorem, Applied Economic Letters, 9, 449-52.

Levin, R. and Reiss, P. (1988) Cost-reducing and demand-creating R\&D with spillovers, Rand Journal of Economics, 19, 538-56.

Metcalfe, S. (1996) The economic Foundations of Technology Policy: Equilibrium and Evolutionary Perspectives, in P. Stoneman (ed.), Handbook of the Economics of Innovation and Technological Change, Blackwell.

Motta, M. (1992) Cooperative R\&D and vertical product differentiation, International Journal of Industrial Organization, 10, 643-61.

Nelson, F. (1977) Censored Regression Models with Unobserved Stochastic Censored Thresholds, Journal of Econometrics, 6, 309-27.

Scherer, F. (1984) Using Linked Patent and R\&D Data to measure Interindustry Tecnology Flows in Z. Griliches (ed.), R\&D Patents and Productivity, University of Chicago Press for the NBER.

Sutton, J. (1998) Technology and market structure, MIT Press. 


\section{FOOTNOTES}

${ }^{1}$ For example Cohen and Klepper (1992) find, in a sample of American manufacturers that overrepresents the biggest firms, that 16 percent of the total observations are zero R\&D expenditures. Moreover, the proportion of business units that report zero expenditures range, for the two digit industries, from 5 to 50 percent. And according to a representative sample of Spanish manufacturing firms, almost 15 percent of the firms with more than 200 workers, and 70 percent of the firms under this size, do not report to perform formal R\&D (see González, Jaumandreu and Pazó (2001).

${ }^{2}$ For a recent theoretical analysis see, for example, the paper of Lee (2002) in which the R\&D intensity is determined jointly by consumer characteristics and the R\&D elasticity of quality, but there is no explanation for the zero expenditure.

${ }^{3}$ Some pioneering experiments to introduce Tobit analysis in the examination of the determinants of innovative activities are Cohen, Levin and Mowery (1987) and Cohen and Klepper (1996). Crépon, Duguet and Mairesse (1998) analyses the links between productivity, innovation and research at the firm level taking into account explicitly that only a small proportion of firms engage in research activities. More recently Parisi and Sembenelli (2001) provide econometric evidence on the elasticity of private R\&D on its price applying a censored panel data regression model to a panel of Italian firms.

${ }^{4}$ In fact, several authors have expressed their worries about the effects of sample selection biases in most of the samples used in the analysis of innovative activities. See, for example, Cohen and Levin (1989) and Griliches (1990).

${ }^{5}$ Most theoretical and empirical work has focussed on process R\&D activities, but empirical evidence point to the dominance of product or mixed R\&D expenditures. For example, Scherer (1984) reports that most industrial R\&D is product-oriented (75.4\% of R\&D expenditures of American firms are allocated to product innovation activities).

${ }^{6}$ The utility specification follows Dixit and Stiglitz (1977), and introduces quality in a way similar to Levin and Reiss (1988), Motta (1992) and Sutton (1998), among others.

${ }^{7}$ See, for example, Arrow (1962) and for a more recent discussion, Metcalfe (1996).

${ }^{8}$ This is a rather usual assumption, that considers R\&D a non-rival input of production. Klette and Griliches (1997) describe this assumption as "once a new product improvement is developed and introduced, no additional resources are needed to produce this improved product as compared to the older version".

${ }^{9}$ This a Dorfman-Steiner type of condition (Dorfman and Steiner (1954)) as that obained by Lee (2001).

${ }^{10}$ These authors modelled the housewives decision to enter the labour market depending on unobserved reservation wages. 